\title{
Results of the 50 First Cases of Robotic assisted Kidney Transplantation compared with Matched-pair Open Cases- A Retrospective Cohort Study
}

\author{
Mireia Musquera $^{1 *}$, Tarek Ajami ${ }^{1}$, Lluis Peri ${ }^{1}$, Laura Izquierdo $^{1}$, Ignacio Revuelta $^{2}$, Fritz Diekmann ${ }^{2}$, Concepción Monsalve ${ }^{3}$ and Antonio Alcaraz $^{1}$ \\ ${ }^{1}$ Department of Urology, Hospital Clinic de Barcelona, Spain \\ ${ }^{2}$ Department of Nephrology and Kidney Transplant, Hospital Clinic de Barcelona, Spain \\ ${ }^{3}$ Department of Anesthesiology, Hospital Clinic de Barcelona, Spain
}

\begin{abstract}
The objective of the study is to compare functional and surgical outcomes of robot assisted (RAKT) and open kidney transplantation (OKT). The first 50 cases of RAKT performed at our center since 2015 were compared with a matched pair of OKT selected from our database.

As a matched- pair comparison was performed; both groups had similar baseline characteristics. Operative time was higher in the RAKT group (213 min vs. 131 $\min \mathrm{p}<0.05)$. One peri-operative graft thrombosis occurred in each group and required transplantectomy. OKT had a higher transfusion rate $(22 \%$ vs. $12 \% \mathrm{p}=0.18)$ and postoperative haematuria ( $18 \%$ vs. $2 \% \mathrm{p}=0.016)$ compared with RAKT. There was no difference regarding creatinine evolution and hospital stay ( 8.7 vs. 9.5 days; $p=0.2)$. The OKT group had a higher incisional hernia rate ( $6 \%$ vs. $2 \%)$, seroma formation $(4 \%$ vs. $0 \%$ ) and uretero-neocystotomy complications (urine leak, stricture) ( $8 \%$ vs. $2 \%$ ) compared with RAKT, none was statistically significant. With a median follow-up time of 1.2 and 4.4 years, the graft survival was $98 \%$ and 96\% for RAKT and OKT, respectively. Despite the small sample size, early experience in RAKT shows less transfusion rate with similar postoperative complication and functional outcomes compared to open standard approach.
\end{abstract}

\section{Introduction}

Nowadays minimally invasive surgical techniques are the standard of care for many procedures due to experience in laparoscopy and robotics. Kidney transplantation surgical technique has not changed significantly over the last decades. Despite the increase knowledge in laparoscopic techniques this has not been spread in kidney transplantation due to the difficulty and low reproducibility rate. On the opposite side, the ability to perform intracorporeal vascular anastomosis assisted by $\mathrm{DaVinci}^{\oplus}$ robotic surgical system (Intuitive Surgical, Inc) has paved the way to start and propagate the robotic assisted kidney transplant (RAKT) program in many centers. To date many observational studies have reported the safety, reproducibility and feasibility of this technique $[1,2]$ and a few have compared the results with the classic open technique [3].

RAKT offers a minimally invasive technique in a special population with elevated risks of surgical complications due to uremia condition and immunosuppressive treatments. Doubts regarding RAKT emerged mainly focusing on costs, effect of the pneumoperitoneum on the graft and hypothermia control. Progressive and subtle changes in the robotic approach technique have resulted in the minimization of the detrimental effect of pneumoperitoneum and improvement of thermal control [4].

Our department has a large experience in open kidney transplantation (OKT) being the first Spanish center performing a deceased donor kidney transplant 1965 by Gil-vernet. We are pioneer in minimal invasive techniques. In that way laparoscopic living donor nephrectomy program was introduced in 2002 with posterior introduction of minimal invasive techniques in 2009 (Assisted transvaginal natural orifice transluminal endoscopic surgery (NOTES)) [5] and (laparoendoscopic single site (LESS)) technique.

Our large experience on OKT and robotic surgery encourage us to start our program of RAKT in 2015, being one of the third European pioneer centers on this technique [2].

The aim of our study was to compare surgical and functional results between this new technique and the former open classic one. The first 50 RAKT performed at our center were compared with an open KT (OKT) matched pair control group.

\section{Patients and Methods}

\section{Study design}

We compared the results of the first 50 living donor RAKT with a matched pair of living donor OKT. Matched pair selection was performed based on baseline variables (age, sex, BMI, number of previous transplants, preemptive condition, type of dialysis, and $\mathrm{ABO}$ compatibility). RAKT were performed between July 2015 and January 2019. To reduce selection bias and minimize the difference, OKT cases

*Correspondence to: Mireia Musquera, Department of Urology, Hospital Clinic de Barcelona,Villarroel 170, Barcelona 08036, Spain, Tel: (+34) 932275400. Ext. 5545; Fax: +34 932275545; E-mail: mmusquer@clinic.cat

Received: January 19, 2021; Accepted: January 27, 2021; Published: January 29, 2021 
were selected from the period comprised between January 2010 and January 2019.

\section{Patient selection}

Since July 2015 living donor RAKT was indicated in recipients without atheromatosis or vascular abnormality.

We reviewed clinical data from donors and recipients. Surgical results were analyzed. Postoperative complications were recorded according to the Clavien-Dindo classification [6]. Graft functional results were assess by creatinine and glomerular filtration (GF).

The Open complex recipients (more than 2 previous transplantation, orthotopic KT, transplantation on aorto-femoral bypass) were excluded.

Surgical technique: For RAKT we used the technique described by Ahlwat and Menon with some changes over the time [7,8]. For instance we changed the perfusion solution from Ringer's lactate to Celsior, because a slow reduction in post RAKT creatinine levels has been noticed in the first cases what were performed in our enter. We reduced pneumoperitoneum pressure from 12 to $10 \mathrm{mmHg}$ after graft reperfusion to reduce possible graft damage $[9,10]$. Kidney was introduced through a periumbilical incision at the beginning of the series, and later on we changed to a pfannenstiel incision that permits a quick open conversion if necessary. In selected cases we used the vagina as a natural orifice for graft insertion. Ureterocystoneostomy is done using extravesical approach.

Open cases were performed using an extraperitoneal approach through a hockey stick incision (Figure 1). In those cases a 6/0 Prolene ${ }^{\circ}$ suture (ETHICON, Johnson \&Johnson Medical) is used for venous and arterial anastomoses. Ureterocystoneostomy is done using Leadbetter Politano technique with MONOCRYL ${ }^{\bullet}$ (ETHICON, Johnson \&Johnson Medical) without stent.

\section{Immunosuppression}

Recipients received immunosuppression with induction treatment with either basiliximab (Simulect ${ }^{\oplus}$, Novartis) or a lymphocyte depleting antibody (Thymoglobuline ${ }^{\star}$ or Grafalon ${ }^{\star}$ ) according to immunogical risk. Moreover, all patients received tacrolimus and steroids and either mycophenolic acid (CellCept ${ }^{\star}$ or Myfortic $^{\star}$ ) or an mTOR inhibitor (rapamune ${ }^{\oplus}$ or Certican ${ }^{\oplus}$ ).

\section{Statistics}

Statistical analysis was performed using SPSS v23; t-Student test was used to compare continuous variables, chi-squared for categorical variables, ANOVA for repeated test to compare creatinine evolution. Statistical significance was defined by $\mathrm{p}<0.05$.

\section{Results}

Baseline characteristics of donors and recipients are described in Table 1. Donors in both groups were mostly females. There was no statistically significant difference between both groups for all variables.

Surgical data is described in Table 2. There was no difference regarding anatomical graft characteristics and warm ischemia time. In the robotic group, 4 cases required end to side arterial anastomosis in the bench surgery to obtain unique vessel. Only one graft had two arteries that were anastomosed independently. None of the grafts in the OKT group required vascular bench surgery. The left iliac fossa was used in three cases from each group, because of previous KT.

The introduction of the kidney in the RAKT group was carried out through an umbilical incision in $36 \%$ of the cases or pfannenstiel
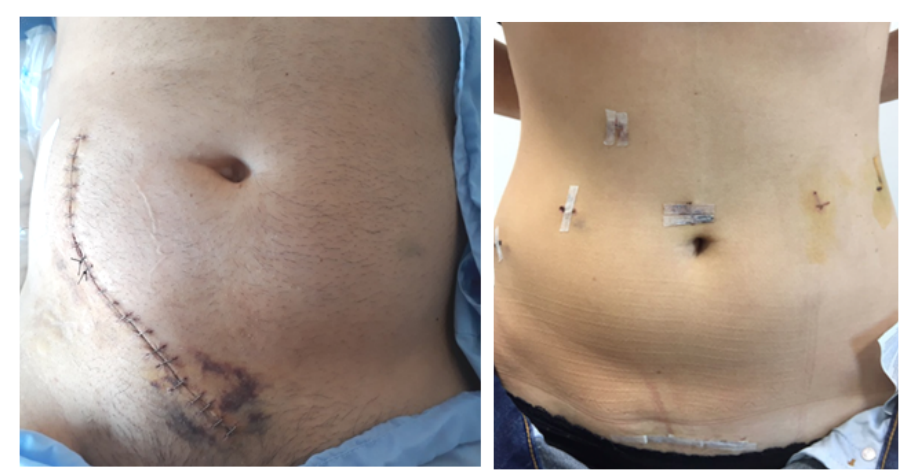

Figure 1. Incisions performed in open KT (left) and RAKT (right)

Table 1. Baseline characteristics of donors and recipients included in each group

\begin{tabular}{|l|l|l|l|}
\hline & Robotic & Open & p value \\
\hline Recipient age (SD) & $47.54(12)$ & $47.88(13)$ & 0.9 \\
\hline Gender (male) & $26(52 \%)$ & $26(52 \%)$ & 1 \\
\hline Recipient BMI (SD) & $25(4.9)$ & $24(3.6)$ & 0.06 \\
\hline Donor age (SD) & $52.9(10.3)$ & $53(9.7)$ & 0.8 \\
\hline $\begin{array}{l}\text { Haploidentic related } \\
\text { donor }\end{array}$ & $26(52 \%)$ & $26(52 \%)$ & 0.5 \\
\hline ABO incompatibility & $7(14 \%)$ & $5(10 \%)$ & 0.76 \\
\hline Preemptive condition & $34(68 \%)$ & $34(68 \%)$ & 1 \\
\hline Previous transplant & $3(6 \%)$ & $3(6 \%)$ & 1 \\
\hline
\end{tabular}

$\mathrm{BMI}=$ Body mass index

Table 2. Surgical data and characteristics of the retrieved grafts from living donors

\begin{tabular}{|l|l|l|l|}
\hline & Robotic & Open & p value \\
\hline $\begin{array}{l}\text { Number of double } \\
\text { arteries (\%) }\end{array}$ & $5(10 \%)$ & $6(12 \%)$ & 0.9 \\
\hline $\begin{array}{l}\text { Number of right } \\
\text { Donor side } \\
\text { nephrectomy (\%) }\end{array}$ & $9(18 \%)$ & $6(12 \%)$ & 0.4 \\
\hline $\begin{array}{l}\text { Operation time in } \\
\text { min (SD) }\end{array}$ & $213(44)$ & $131(33)$ & $<0.005^{*}$ \\
\hline $\begin{array}{l}\text { Warm ischemia in } \\
\text { minutes (SD) }\end{array}$ & $3.18(1.7)$ & $2.96(1.4)$ & 0.5 \\
\hline $\begin{array}{l}\text { Robotic console time } \\
\text { in minutes (SD) }\end{array}$ & $103.2(27)$ & - & \\
\hline
\end{tabular}

${ }^{*} \mathrm{p}$ value is statistically significant at 0.05 .

incision in 54\%. In three cases, the kidney was introduced through the vagina.

The total surgical time was significantly higher in the robotic group, with a mean time of 213 minutes $(\mathrm{SD}=44)$ compared with 131 minutes $(\mathrm{SD}=33)$ for the open group $(\mathrm{p}<0.005)$. Rewarming time was not assessed in open group, in the robotic group was registered for quality control. Mean rewarming time in the RAKT group was less than 50 minutes (Table 2).

Three RAKT cases were converted to the open approach due to abnormal perfusion. One case ended with vein thrombosis and required transplantectomy, in the second case perfusion was spontaneously resolved and the third one required graft revascularization.

Early (30-day) complications are described in Table 3. We found a significantly higher incidence of post-operative haematuria in OKT, mostly treated conservatively $(\mathrm{p}<0.016)$.

Two cases in each group required intervention for bleeding. Treated by percutaneous capsular and epigastric artery embolization in the 


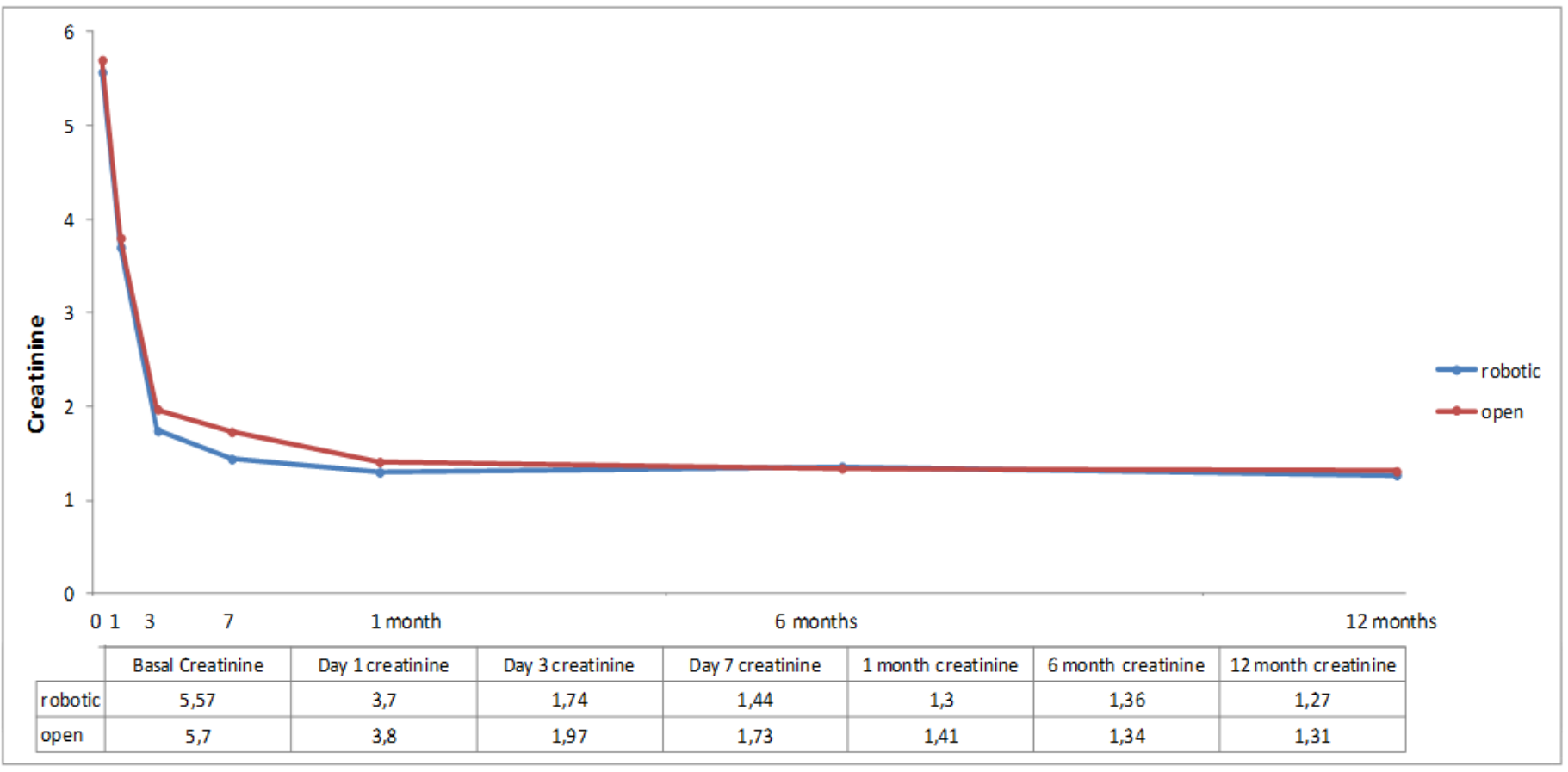

Figure 2. Creatinine evolution curves of both groups till first year of follow-up

RAKT group and requiring surgical revision in the open one. One early transplantectomy (24 hours) was performed due to vein thrombosis in each group.

One patient in the open group develops urine leak during the postoperative period that required surgery.

None of the analyzed recipients presented wound infection. However, two patients in the open group required seroma drainage.

Both groups presented a similar mean length of hospital stay (8.7 days for RAKT vs. 9.5 for OKT; $\mathrm{p}=0.2$ ).

Late complications are described in table 4. A low percentage of symptomatic lymphoceles was observed in both groups. Lymphoceles required surgical marsupialization. Inisional hernia rate was slightly higher in the open group compared with the robotic one, but without significant differences. Ureteral stricture requiring surgical treatment was 3 times more frequent in the open group. One case in the open group developed ureteropelvic junction syndrome.

Regarding graft function, no statistical difference was found between both groups. One patient presented delayed graft function in the open group (Table 5). The evolution of postoperative creatinine is shown in Figure 2. There were no differences in terms of long-term immunosuppression between the two groups $(\mathrm{p}=0.18)$.

With a median time of follow-up for 1.2 and 4.4 years, the graft survival was $98 \%$ and $96 \%$ for RAKT and OKT, respectively.

\section{Discussion}

Since the first RAKT reported in 2010 by Giulianotti, et al. [11], many centers have implemented this technique as an alternative method to open approach. To date nearly all published data is based on descriptive series and few of them compared the results with the open approach [12].
Table 3. Early and late complications according de Clavien Dindo classification

\begin{tabular}{|c|c|c|c|}
\hline & Robotic & Open & p value \\
\hline \multicolumn{4}{|l|}{$\underline{\text { Clavien I }}$} \\
\hline Ileus & $1(2 \%)$ & 0 & 1 \\
\hline Hematuria & $1(2 \%)$ & $9(18 \%)$ & $0.016^{*}$ \\
\hline Seroma formation & 0 & $2(4 \%)$ & 0.5 \\
\hline \multicolumn{4}{|l|}{ Clavien II } \\
\hline Blood transfusion & $6(12 \%)$ & $11(22 \%)$ & 0.18 \\
\hline \multicolumn{4}{|l|}{$\underline{\text { Clavien IIIa }}$} \\
\hline $\begin{array}{l}\text { Selective } \\
\text { embolization }\end{array}$ & $2(4 \%)$ & 0 & 0.5 \\
\hline \multicolumn{4}{|l|}{$\underline{\text { Clavien IIIb }}$} \\
\hline $\begin{array}{l}\text { Transplantectomy } \\
\text { due to vein } \\
\text { thrombosis }\end{array}$ & $1(2 \%)$ & $1(2 \%)$ & 1 \\
\hline $\begin{array}{l}24 \text { hour re- } \\
\text { intervention }\end{array}$ & 0 & $2(4 \%)$ & 0.5 \\
\hline Urine leak & 0 & $1(2 \%)$ & 1 \\
\hline $\begin{array}{l}\text { Ureterovesical } \\
\text { stricture }\end{array}$ & $1(2 \%)$ & $3(6 \%)$ & 0.36 \\
\hline Incisional Hernia & $1(2 \%)$ & $3(6 \%)$ & 0.4 \\
\hline$\underline{\text { Clavien IV }}$ & 0 & 0 & \\
\hline
\end{tabular}

$*$ p value is statistically significant at 0.05 .

Table 4. Functional outcomes regarding rates of delayed graft function, acute rejection rates and overall graft survival

\begin{tabular}{|l|l|l|l|}
\hline & Robotic & Open & p value \\
\hline DGF & 0 & $1(2 \%)$ & 1 \\
\hline $\begin{array}{l}\text { Tracer renogram } \\
\text { uptake }\end{array}$ & 822 & 1070 & $0.012^{*}$ \\
\hline Acute Rejection & $3(6 \%)$ & $7(14 \%)$ & 0.182 \\
\hline Graft survival & $98 \%$ & $96 \%$ & $\mathrm{p}>0.58$ \\
\hline
\end{tabular}

$\mathrm{DGF}=$ delayed graft function

$* p$ value is statistically significant at 0.05 . 
We compared our first 50 cases of RAKT with a matched pair of open approach. Mean surgical time was higher in the robotic group but this did not cause differences regarding graft function This longer operative time can be explained because the robot docking process and the learning curve. The mean rewarming time, very critical in this surgery, was inferior to 50 minutes in the robotic group (data not available for open approach), similar data to other RAKT series published before [2]. We noticed a progressive decrease in rewarming and surgical time over cases. Currently, in most RAKT surgical time is below two hours, being competitive to the open approach.

RAKT permits to reduce the size of the incision in this special population which is sensible to wound infections and incisional hernia [13]. This is even more important in obese patients who usually require big incisions to perform an OKT. The mean BMI in our series are normal $(<25)$, however, some groups have analyzed RAKT results in obese patients with promising results [14]. As in all innovative surgeries, we learned case by case and we adopted some surgical changes, to facilitate and ameliorate the initial technique [15]. One of those changes has been the kidney introduction site. We started using periumbilical incision and now we use a Pfannenstiel approach, or even transvaginal in selected recipients. Pfannenstiel incision permits a quicker location of the kidney and a lateral prolongation of the incision in case of urgent conversion to the open technique, which gives good exposure of the graft. Another reason for this change is the proved higher rate of hernia in periumbilical incision compared to Pfannestiel [16]. In our study no significative differences between both techniques were seen in terms of post-operative hernia $(\mathrm{p}=0.4 \%)$. Our group has a large experience using natural orifices for organ removal [5]. The use of the vagina as a channel for kidney insertion permits to reduce even more incisions. The use of the vagina has been already described in a small case series [17] with good results.

We lost one kidney in each group; both initially required revascularization but finally ended with transplantectomy 24 hours later. Two others cases were converted to open approach because of a bad perfusion noticed during ureteral reimplantation. In some open cases we have advice bad perfusion during ureteral anastomosis, that mostly are related to decrease blood pressure or in some cases due to arterial valve compression. Open approach permit a quick detection, for this reason, in RAKT we currently perform an immediate Doppler ultrasound to confirm good graft perfusion. It is important to emphasize that these problems occurred at the beginning of our series; similar results were found in RAKT- European Robotic Urological Society (ERUS) group [2].

The higher incidence of hematuria in the open group is directly related to the type of anastomoses. It is well known that an intravesical technique has a higher risk of presenting hematuria mainly because of additional cystotomy from which bleeding can arise [18]. After this analysis we could plan to change our open technique but we are really confident with it, and usually the hematuria solved spontaneously. RAKT in our series has a lower rate transfusion compared to open approach. Our robotic results are similar to those described in the literature [3]. In addition, we found lower rates of urinary leakage and ureteral stenosis in the RAKT group, although not reaching statistical significance. The rate of stenosis in our OKT group was similar to that published in other series (0.6-10.6\%) [19], this could be explained by the hypotheses of hypoperfusion of the distal ureter because a longer segment is used. This has been confirmed in a metanalysis by Alberts, et al. [18].
In our series no differences in length of hospital stay have been found, but we noticed a shorter stay for recent RAKT cases probably due to surgical improvement and changes in medical management (early removal of drainage and bladder catheter).

Wound complication rates were higher in the open group although the difference was not significant. No surgical site infection (SSI) was detected in either group; instead, higher tendency of incisional hernia (IH) was found in the open group. The hernia in the RAKT group was in a periumbilical incision. Notice that in our series the $\mathrm{IH}$ in the open group is lower than others published series (9-16\%) [13].

Oberholzer, et al. [14], published the first comparative study between open and robotic transplants. However, the study was limited to obese patients ( 28 patients) with a 5 year follow up. The recipients in the robotic group had higher BMI and they would have been refused transplantation in the open approach. The authors detected a significantly higher SSI ( 0 vs. $28 \%)$ in the open group $(\mathrm{p}<0.01)$.

As regards to functional results (delayed graft function, acute rejection rates and overall graft survival), we did not find any differences, although the surgical time in the robotic group was longer. Oberholzer, et al. [14] found a higher creatinine value at discharge in the robotic approach $(2 \mathrm{mg} / \mathrm{dl}$ vs. $1.2 \mathrm{mg} / \mathrm{dl} ; \mathrm{p}=0.04)$ but with a similar graft function after six month follow up with $100 \%$ graft survival at 3 years. The previous published series had similar levels of creatinine during follow up [2]. Creatinine evolution in our series was equivalent in both groups.

This study have some limitations; the first inherent to the retrospective nature of the analysis. This condition has not permitted to evaluate post-operatory pain; Togcu, et al. [3] has conducted a prospective analysis in which pain scores were significantly lower in the robotic group. Second, the long period of time comprised between 2010 and 2019 was due to the fact that most of the open cases were done during the first 5 years and the RAKT during the last 4 . Although the surgical technique for OKT has not changed at our center during the period 2002-2019, the medical management of KT has undergone certain modifications such as the introduction of mTOR inhibitors. For this aim, we reduced the selection period of OKT between 2010- 2019.

\section{Conclusion}

This is the first European study in which open and robotic kidney transplants are compared as matched pair cases. Albeit its limitations, it shows no difference regarding either functional results or postoperative outcomes between RAKT and OKT. The robotic approach is an attractive method for kidney transplantation, but further studies are needed to consider it as a standard approach.

\section{Funding}

Authors have declared no funding sources for this study.

\section{Conflicts of interest}

The authors declare that they have no conflict of interest.

\section{References}

1. Peri L, Musquera M, Izquierdo L, Fernández-Ramón C, Melnick A, et al. Robotic kidney transplantation. Arch Esp Urol 70: 462-467. [Crossref]

2. Musquera M, Peri L, Ajami T, Campi R, Tugcu V, et al. (2020) Robot-assisted kidney transplantation: update from the European Robotic Urology Section (ERUS) series. BJU Int. [Crossref] 
3. Tugcu V, Sener NC, Sahin S, Yavuzsan AH, Akbay FG, et al. (2018) Robot-assisted kidney transplantation: comparison of the first 40 cases of open vs robot-assisted transplantations by a single surgeon. BJU Int 121:275-280. [Crossref]

4. Alcaraz A, Peri L, Izquierdo L, Musquera M (2017) Is robotic kidney transplant the near future? Eur Urol 72: 218-219. [Crossref]

5. Alcaraz A, Musquera M, Peri L, Izquierdo L, García-Cruz E, et al. (2011) Feasibility of transvaginal natural orifice transluminal endoscopic surgery-assisted living donor nephrectomy: is kidney vaginal delivery the approach of the future? Eur Urol 59: 10191025. [Crossref]

6. Dindo D, Demartines N, Clavien PA (2004) Classification of surgical complications: a new proposal with evaluation in a cohort of 6336 patients and results of a survey. Ann Surg 240: 205-213. [Crossref]

7. Menon M, Sood A, Bhandari M, Kher V, Ghosh P, et al. (2014) Robotic kidney transplantation with regional hypothermia: a step-by-step description of the Vattikuti Urology Institute-Medanta technique (IDEAL phase 2a). Eur Urol 65: 991-1000. [Crossref]

8. Menon M, Abaza R, Sood A, Ahlawat R, Ghani KR, et al. (2014) Robotic kidney transplantation with regional hypothermia: evolution of a novel procedure utilizing the IDEAL guidelines (IDEAL phase 0 and 1). Eur Urol 65: 1001-1009. [Crossref]

9. Chiu AW, Chang LS, Birkett DH (1995) The impact of pneumoperitoneum, pneumoretroperitoneum, and gasless laparoscopy on the systemic and renal hemodynamics. J Am Coll Surg 181: 397-406. [Crossref]

10. Musquera M, Peri L, Ajami T, Revuelta I, Izquierdo L, et al. (2020) Results and Lessons Learned on Robotic Assisted Kidney Transplantation. Biomed Res Int Sep 2020: 8687907. [Crossref]
11. Giulianotti P, Gorodner V, Sbrana F, Tzvetanov I, Jeon H, et al. (2010) Robotic transabdominal kidney transplantation in a morbidly obese patient. Am J Transplant 10: 1478-1482. [Crossref]

12. Maheshwari R, Qadri S, Rakhul LR, Chaturvedi S, et al. (2020) Prospective Nonrandomized comparison between Open and Robot Assisted Kidney Transplantation: Analysis of mid-term functional outcomes. J Endourol 34: 939-945. [Crossref]

13. Wagenaar S, Nederhoed JH, Hoksbergen AW, Bonjer HJ, Wisselink W, et al. (2017) Minimally invasive, laparoscopic, and robotic-assisted techniques versus open techniques for kidney transplant recipients: a systematic review. Eur Urol 72: 205-217. [Crossref]

14. Oberholzer J, Giulianotti P, Danielson KK, Spaggiari M, Bejarano-Pineda L, et al. (2013) Minimally invasive robotic kidney transplantation for obese patients previously denied access to transplantation. Am J Transplant 13: 721-728. [Crossref]

15. Sood A, Hakim DN, Hakim NS (2016) Consequences of recipient obesity on postoperative outcomes in a renal transplant: a systematic review and meta-analysis. Exp Clin Transplant 14: 121-128. [Crossref]

16. Lee L, Abou-Khalil M, Liberman S, Boutros M, Fried GM, et al. (2017) Incidence of incisional hernia in the specimen extraction site for laparoscopic colorectal surgery: systematic review and meta-analysis. Surg Endosc 31: 5083-5093. [Crossref]

17. Musquera Felip M, Ajami Fardoun T, Peri Cusi L, Alcaraz Asensio A (2021) Technique Description and Outcomes of Robotic Transvaginal-Assisted Living Donor Kidney Transplantation. Urol Int 105: 148-154. [Crossref]

18. Alberts VP, Idu MM, Legemate DA, Pes MPL, Minnee RC, et al. (2014) Ureterovesical Anastomotic techniques for Kidney transplantation: a systematic review and metaanalysis. Transpl Int 27: 593-605. [Crossref]

19. Breda A, Budde K, Figueiredo, García EL, Olsburgh J, et al. (2019) Rena Transplantation. European Association of Urology (EAU) Guidelines on kidney transplantation.

Copyright: (C2021 Musquera M. This is an open-access article distributed under the terms of the Creative Commons Attribution License, which permits unrestricted use, distribution, and reproduction in any medium, provided the original author and source are credited. 